\title{
DÜBLIN
}

Technological University Dublin

ARROW@TU Dublin

\section{Challenges in Model Development for Meat Composition Using Multipoint NIR Spectroscopy from At-Line to In-Line Monitoring}

\author{
Yash Dixit \\ Technological University Dublin \\ Maria Piedad Casado-Gavalda \\ Technological University Dublin, maria.casado@tudublin.ie \\ R. Cama-Moncunill \\ Technological University Dublin
}

See next page for additional authors

Follow this and additional works at: https://arrow.tudublin.ie/schfsehart

Part of the Food Science Commons

\section{Recommended Citation}

Dixit, Y. et al (2017). Challenges in model development for meat composition using multipoint NIR spectroscopy from at-line to in-line monitoring. Journal of Food Science, 82(7), pp.1557-1562. doi:10.1111/1750-3841.13770

This Article is brought to you for free and open access by the School of Food Science and Environmental Health at ARROW@TU Dublin. It has been accepted for inclusion in Articles by an authorized administrator of ARROW@TU Dublin. For more information, please contact arrow.admin@tudublin.ie, aisling.coyne@tudublin.ie, gerard.connolly@tudublin.ie.

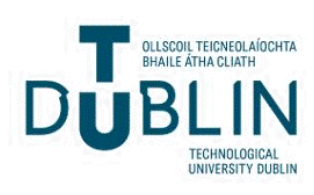




\section{Authors}

Yash Dixit, Maria Piedad Casado-Gavalda, R. Cama-Moncunill, Patrick Cullen, and Carl Sullivan 
Challenges in model development for meat composition using multipoint NIR spectroscopy from at-line to in-line monitoring

Y. Dixit ${ }^{\mathrm{a}}$, *, Maria P. Casado-Gavalda ${ }^{\mathrm{a}}$, R. Cama-Moncunilla ${ }^{\mathrm{a}}$ P. J. Cullen ${ }^{\mathrm{a}, \mathrm{b}}$, Carl Sullivan ${ }^{\mathrm{a}}$

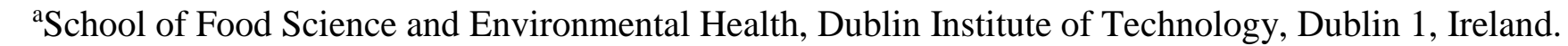

$7 \quad{ }^{\mathrm{b}}$ School of Chemical Engineering, University of New South Wales, Sydney, Australia.

$8 \quad$ Y. Dixit

9 School of Food Science and Environmental Health,

$$
\begin{aligned}
& \text { Tel: }+35314024543 \\
& \text { E-mail: yash.dixit@ mydit.ie } \\
& \text { Word count of text, “4940”}
\end{aligned}
$$


Abstract: This study evaluates the efficiency of multipoint Near Infrared spectroscopy (NIRS) to predict the fat and moisture content of mixed minced beef samples both in at-line and on-line modes. Additionally, it aims at identifying the obstacles that can be encountered in the path of performing inline monitoring. Near Infrared (NIR) reflectance spectra of minced beef samples were collected using a NIR spectrophotometer, employing a Fabry-Perot interferometer. Partial least squares regression (PLSR) models based on reference values from proximate analysis yielded calibration coefficients of determination $\left(R_{c}^{2}\right)$ of 0.96 for both fat and moisture. For an independent batch of samples, fat was estimated with a prediction coefficient of determination $\left(R_{p}^{2}\right)$ of 0.87 and 0.82 for the samples in at-line and on-line modes respectively. All the models were found to have good prediction accuracy, however, a higher bias was observed for predictions under on-line mode. Overall results from this study illustrates that multipoint NIR systems combined with multivariate analysis has potential as a Process Analytical Technology (PAT) tool for monitoring process parameters such as fat and moisture in the meat industry, providing real-time spectral and spatial information.

Keywords: Near Infrared Spectroscopy; minced beef; At/On-line modes; Partial Least Squares, external factors

Practical Application: The new multipoint NIR device illustrates potential as an in-line quality monitoring tool for meat processing industry. Further developments in the field of NIR optics it could be possible to use this device in an industrial environment.

\section{END PAGE 2}




\section{Introduction}

Meat is considered as the most important livestock product because of its high nutritional value. The significance of meat is related to its high quality protein, which contains all the essential amino acids, vitamins and minerals. The demand for meat and meat products is growing in many parts of the world because of the growing population. It is expected that world meat production will double by 2050, which is mostly driven by demand in developing countries (FAO).

Minced meat is one of the most popular meat products from the producer and consumer points of view because of its known consistency as a cost-effective and pleasing food (Morsy and Sun 2013). Minced beef in particular is a major ingredient for a variety of products such as hamburgers, sausages and meat balls. It is available and priced in the market based on varying fat levels. Sausages for example are a product with the primary aim of presenting large fat proportions in a palatable way. Moreover when preparing more 'noble' cuts of meat, trimmings are produced from which the fat is removed. These can be minced together to produce products which are more desirable to the consumers because of their different texture than that of the whole meat (Ranken 2000).

Fats are also important precursors of meat aroma and are an essential component for flavour development. Fat is associated with the species-specific flavour of beef, playing a significant role on the characteristic taste of beef meat (Kerth and others 2015). It can also be related to an off flavour due to lipid oxidation (Boylston and others 2012). The distribution of fat within the lean portion of meat is defined as marbling. Marbling and fatness are used as meat quality indicators, with meat having high marbling considered to be desirable due to the effects of fat on flavour and tenderness (Toldrá 2010).

The quality of meat is defined by consumer acceptability and involves appearance characteristics (such as color, amount of fat, amount of visible water) and also tenderness, juiciness and flavor. As fat contributes considerably to the tenderness and flavor consistency of ground beef it is of paramount importance to have the correct proportions of fat (Toldrá 2010). Authenticity of the food available in the market is a major requirement to meet the demands of consumers and assuring compliance with the government regulations and safety standards. Thus, to ensure the correct quality and amount of fat and other chemical elements in minced meat, its chemical composition should be analyzed (Tøgersen and others 2003).

The use of PAT (Process Analytical Technology) tools provides a major opportunity for the meat industry to enhance the competitiveness of its processing industries and gain added value in the worldwide market (Misra and others 2015). The unique features obtained from NIR spectra makes the approach suitable for PAT applications (Bakeev 2010). NIRS (Near infrared spectroscopy) is a sensing solution which provides real time quality control and assurance. NIRS is widely used in the food and pharmaceutical industries, primarily due to its advantages including; speed of analysis, accuracy, little or no sample preparation and non-contact approach (Gowen and others 2008; Prado and others 2011). It has been proved to be successful for the prediction of chemical composition parameters, such as fat, water and protein content in the meat industry, which could speed up the quality assurance procedure of these products (Prieto and others 2006b). NIRS is a convenient tool not only for characterizing foods, but also for quality measurements and process control (Alexandrakis and others 2012). The use of multipoint NIRS systems have the added advantage of providing spatial information, a significant factor when dealing with heterogeneous samples such as meat (Dixit and others 2016b). There is considerable interest to use NIR on-line to predict chemical parameters in the meat industry. However, distances between the production line and the NIR setup and errors introduced by sampling have been major obstacles in this regard. Continuous efforts are being made to improve NIR on-line application due to the meaningful spectra provided by this procedure (Andres and others 2007). Predicting chemical traits of minced beef while in motion with the use of NIRS technology would be of great advantage to moving production lines such as conveyors and hopper systems and studies have been conducted in this regard (Wold and others 2011). The many advantages offered by NIRS would make it an indispensable technology for meat industries. Moreover, the measurement of several constituents simultaneously without any sample preparation and pre-treatment adds value to this efficient technique. 
Most commercially available NIR spectroscopy devices are limited to single point analysis and thus spatial information is ignored. If the sample is heterogeneous, such as meat, a single value might not be able to characterize the bulk sample (Wold and others 2011). Moreover, present industrial systems in the market such as multi-spectral imaging systems are placed fixed to the conveyor belt measuring in only one endpoint of the production line. Also, the mentioned systems could only be used at a fixed specified height and measure single sample at a time, whereas the multipoint NIR system used in this study illustrates the potential to monitor different endpoints (various samples) at the same time using a single system. Most of the multipoint NIR systems used in the previous studies are quasi-simultaneous i.e. only one probe operates at a time and the particular probe is activated using a fiber switch or they used two different spectrophotometers (Scheibelhofer and others 2013). The probes of the NIR spectrophotometer used in the current study perform concurrent measurements independently Additionally the system could use different standoff distances and different light sources for individual probes, the probes could be placed inside a drying or freezing chamber for a specific temperature range. This is of importance in order to monitor the whole production process at its different stages and detect any abnormality on the compositional readings before the product continues to the next stage. The multipoint feature of the current system provides various advantages such as; probe flexibility, spatial information, overcoming sample heterogeneity and many more.

For NIR-based analyses, the following modes of measurements are commonly used; (a) Off-line: Analyses the sample away from the production line, typically in a quality control (QC) laboratory, (b) At-line: Random samples are manually removed from the production line and analyzed nearby, (c) Online: The samples are diverted from the production line to be analyzed directly in the running sample stream and to be returned back to the production line after analysis and (d) In-line: Analyzing the sample within the running production line (Food and Drug Administration Center for Drug Evaluation and Research (CDER) MAR 2015). The current industrial scenario requires NIR to perform in-line monitoring. However, various challenges and obstacles need to be understood in order to overcome them. The aim of this study is to test the performance of multipoint NIRS under at-line and on-line modes for predicting primarily fat along with moisture content of minced beef samples with the aid of chemometrics. Additionally, the study illustrates challenges encountered when shifting from at-line to on-line modes for a minced beef quality monitoring system.

\section{Materials and methods}

In order to ensure reproducibility of the results, the methodologies described in this section were conducted in three independent experiments, further on referred as batch 1, batch 2 and batch 3 .

\section{Sample Preparation}

Sample preparation was performed following the methodology described by (Dixit and others 2016a). Briefly, fifty-four minced samples ranging from 0 to $100 \%(\mathrm{w} / \mathrm{w})$ in fat trimmings content were prepared in increments of $20 \%(\mathrm{w} / \mathrm{w})$ and in triplicates. Three independent experiments (18 samples per independent experiment) were studied. Each sample comprised of approximately $15 \mathrm{~g}$ of a mixture of minced lean and minced fat beef trimmings.

Initially, fresh striploin beef steaks weighing approximately $1.5 \mathrm{Kg}$ were purchased from a local butcher's shop in Dublin city. On the same day, the steaks were carefully cut in order to accurately separate the lean from the fat beef trimmings. The lean beef and fat trimmings samples were first cut into small cubes and minced separately using an electric food processor, which was carefully cleaned using an antibacterial washing liquid and properly dried before each use. The earlier described mixtures were then prepared using the already minced lean and fat trimmings. These were then minced further in order to ensure homogeneity and placed in sealed disposable aluminium dishes to be stored overnight at $4{ }^{\circ} \mathrm{C}$. 
Proximate analysis of the minced lean beef and minced fat beef trimmings samples were carried out using standard methods of the AOAC (2000): moisture content (method 950.46) and fat (method 960.39).All the analyses were performed in triplicates.

\section{NIR spectra acquisition}

The day after sample preparation, samples were removed from storage at $4{ }^{\circ} \mathrm{C}$ and allowed to reach room temperature before spectroscopic analysis. Measurements were conducted at room temperature to illustrate the ability of multipoint NIRS to work in NTP (Normal Temperature and Pressure) conditions which could be beneficial for its application in an industrial environment. The NIR spectrophotometer used for this study operates in the wavelength range of 1515 to $2100 \mathrm{~nm}$ with a resolution of $5 \mathrm{~nm}$. The probes were placed at a distance of 2-3 $\mathrm{mm}$ from the sample and its surface was flattened to reduce the impact of distance difference between the sample and the probes. Measurements were first taken under static conditions in order to mimic a typical at-line analysis scenario in a production line followed by the same procedure under motion conditions, mimicking a typical on-line analysis scenario in a production line. Motion was achieved with the aid of a small rotating device (TLD-TEC, Germany) and a controllable speed of $100 \mathrm{rpm}(0.074 \mathrm{~m} / \mathrm{s})$. Measurements were performed with the 4 probes arranged in a square shape, set perpendicular with the samples and cleaned regularly using acetone. For each sample, measurements were taken at five different regions of the sample surface, acquiring 20 measurements per sample (4 probes by 5 sample regions). Spectral acquisition and file conversion from reflectance to absorbance values were performed operating the manufacturer's software (MultiEye Piezo, VTT, Finland).

\section{Data analysis}

Raw absorbance data was exported in .txt format and imported into R (R Core Team 2014) for further data pre-processing and multivariate analysis. A low signal to noise ratio could be observed at the end of the spectral data, only the range of wavelengths from 1515 to $2000 \mathrm{~nm}$ was employed for the calculations. Initially, standard normal variate (SNV) transformation and Savitzky-Golay smoothing were applied to remove noise from the acquired spectra. A Savitzky-Golay filter of order zero with a moving average window of 11 points was selected along with a polynomial of $3^{\text {rd }}$ degree. The resulting processed data was analyzed and modelled using partial least squares regression (PLSR) with the purpose of developing calibration models for predicting fat and moisture content, relevant for quality purposes in a typical meat production line.

Absorption bands in the NIR region are broad and heavily overlapped, being difficult to distinguish the individual peaks through visual inspection (Cozzolino 2015). In order to overcome this, chemometric techniques such as PLSR have been used. PLSR analysis was used to find a mathematical relationship between absorbance at different wavelengths and the chemical attributes: fat and moisture. The PLSR was conducted using the package "pls" in R. The procedure has two steps, the first is the calibration and the second is the prediction that tests the calibration model (Meza-Marquez and others 2010). Models for fat and moisture composition of beef for at-line and on-line modes were developed respectively. In order to develop the calibration models, processed data acquired for batch 1 and batch 2 were used, along with the reference values fat and moisture obtained from the proximate analysis. The data acquired from batch $3(n=18)$ for both at-line and on-line modes was used as a validation sample set for the calibration models built for at-line and on-line modes respectively. Calibration models were developed considering a cross validation using leave-one-out method in order to avoid either over- or under-fitting of the model. PLS models were created for fat and moisture content under both at-line and on-line modes (Moreira and others 2015). The best PLSR models were chosen at the minimum values of both standard errors of calibration (SEC) and standard errors of cross validation (SECV). The corresponding values of both coefficients of determination in calibration $\left(R_{c}^{2}\right)$ and in cross validation $\left(R_{c v}^{2}\right)$ were maximum for a best fitted model (Morsy and Sun 2013). Prediction ability of the models 
were determined using the statistical indices; the bias corrected standard error of prediction (SEP), residual predictive deviation (RPD) and coefficients of determination in prediction $\left(R_{p}^{2}\right)$ (Makky and Soni 2014).Statistical indices SEC and SEP are defined as follows:

$S E C=\sqrt{\frac{\sum_{i=1}^{n_{C}}\left(\hat{y}_{i}-y_{i}\right)^{2}}{\left(n_{c}-1\right)}}$

$S E P=\sqrt{\frac{\sum_{i=1}^{n_{v}}\left(\hat{y}_{i}-y_{i}-\text { bias }\right)^{2}}{\left(n_{v}-1\right)}}$

Where $n_{c}$ is the number of data samples for calibration, $n_{v}$ is the number of data samples for validation, $\hat{y}_{i}$ is the prediction value and $y_{i}$ is the measured value. The average differences between predicted and actual values were considered as bias.

$$
\begin{aligned}
\text { bias } & =\left(\frac{\sum_{i=1}^{n_{v}}\left(\hat{y}_{i}-y_{i}\right)^{2}}{n_{v}}\right) \\
R P D & =\frac{S D_{y}}{R M S E P}
\end{aligned}
$$

Where $S D_{y}$ is the standard deviation of the calculated set.

\section{Results and Discussion}

\section{Proximate analysis}

Chemical analysis of fat and moisture for both lean beef and fat beef trimmings were calculated and reported per batch in Table 1. Moisture and fat were the major components present, which will therefore be expected to have an important contribution to the corresponding spectrum from each sample. All results in Table 1were in good agreement with those reported in the literature (ElMasry and others 2013; Morsy and Sun 2013). Samples were analyzed in the same laboratory using the same analytical balance.

\section{NIR Spectra}

Fig.1 shows the SNV transformed and smoothed spectra of minced beef samples at different fat levels both in at-line as well as in on-line modes. The variation between different fat levels is clearly visible between the wavelength range of 1700-1800 nm (Fig.1 a and b). The absorption bands at 1716 and 1758 $\mathrm{nm}$ shows $\mathrm{C}-\mathrm{H}$ first stretching tones, which are characteristic of fat and fatty acids in samples and are in accordance with studies reported by Morsy and Sun (2013), Hoving-Bolink and others (2005) and Cozzolino, De Mattos, and Martins (2002). The absorption band at $1448 \mathrm{~nm}$ is related to second $\mathrm{O}-\mathrm{H}$ stretching overtone, characteristic of the absorption of water and therefore moisture content in the samples (Prieto and others 2009). The end portion of the O-H stretching peak is visible from 1515 to $1650 \mathrm{~nm}$ (Fig.1 a and b). The absorption band at $1690 \mathrm{~nm}$ is associated with N-H overtones, which are related to protein content of the samples. It is difficult to identify this particular band in the spectra as it is very close to the fat and water absorption bands. C-H first overtone which exists between 1600 and $1800 \mathrm{~nm}$, could be related to ash content but it is difficult to recognize it by visual inspection (Bruun and others 2010). The three independent experiments reflect similar spectral features at the wavelength regions of interest, hence overcoming the sample variability of independent batches.

The noise in the NIR spectra for on-line mode (Fig.1 b) could be due to a variation in the amount of diffused light entering the NIR probes which could be related to height differences encountered by the probes while the samples were in motion. In an industrial environment, external factors such as ambient temperature, spectrophotometer temperature, stray light, wavelength shifts and many other factors affects the robustness of the model as well as their prediction accuracy (Alexandrakis 2012). In order to build a robust calibration model for real time conditions, these factors need to be overcome. 


\section{PLSR: Loadings plot}

Fig. 2 shows the main PLS loadings plot for the fat model in at-line mode. The two main PLS factors explained almost $96 \%$ of the total variance with a $R_{c v}^{2}$ of 0.96 . First PLS factor explained approximately $91 \%$ of the total variance which includes the absorption peaks at 1728 and $1768 \mathrm{~nm}$, associated with fat content in minced beef samples. The first PLS factor also had the greatest contribution to the loading values. The second factor explains about $5 \%$ of the total variance; however it includes the tail portion of the absorption peak at $1450 \mathrm{~nm}$ and also the peak at $1950 \mathrm{~nm}$, associated with moisture content of samples. Hence, the PLS loadings plot was able to represent the absorption peaks related to fat and moisture content of the samples with a good accuracy. The main PLS loadings were also observed for fat model in on-line mode with two main PLS factors explaining almost $90 \%$ of the total variance. Similar values were observed for moisture model in both modes. All these results were in accordance with studies conducted by ElMasry and others (2013), Morsy and Sun (2013) and Dixit and others (2016a).

\section{PLSR: Calibration model}

A summary of the PLS models (batch 1 and 2) containing coefficients of determination, residual predictive deviation and standard errors for both calibration $\left(R_{c}^{2}, \mathrm{RPD}, \mathrm{SEC}\right)$ and cross validation $\left(R_{c v}^{2}\right.$, RPD, SECV ) along with the number of PLS components used for all the four models under at-line and on-line modes is shown in Table 2. Higher values of $R_{c}^{2}, R_{c v}^{2}$ and RPD values; lower values of SEC and SECV confirms a good fit for the models (Table 2). PLSR models for fat showed a good fit in both atline and on-line modes with a $R_{c v}^{2}$ of 0.96 and 0.95 and SECV of 4.30 and 4.89 respectively. Moisture models also showed fairly accurate fits in both modes with a $R_{c v}^{2}$ in the range of 0.96-0.98 and were in accordance with the results reported by ElMasry and others (2013) and Tøgersen and others (1999). It can be observed that for the fat and moisture models based on the processed data obtained from the online mode, SEC and SECV values were a fraction higher which could be attributed to different reasons; changes in the presentation of the samples to the probe, instability (mechanical vibrations) during motion provided by the device and variation in the amount of diffused reflected light entering the NIR probes. Apart from the mentioned reasons other external factors could also affect the measurements such as; stray light, ambient temperature, spectrophotometer temperature and others.

\section{PLSR: Model validation}

Standard errors for prediction (SEP) along with its coefficient of determination $\left(R_{p}^{2}\right), \mathrm{RPD}$ and bias values for the validation set (batch 3 ) in both at-line and on-line modes are shown in Table 2. In atline mode fat was well predicted with a $R_{p}^{2}$ and a RPD of 0.87 and 2.86 respectively. Moisture also showed good predictions yielding a $R_{p}^{2}$ and a RPD of 0.92 and 3.63 respectively (Table 2). In on-line mode good predictions were observed for fat yielding a $R_{p}^{2}$ of 0.82 and a RPD of 2.43. Moisture was predicted with a $R_{p}^{2}$ of 0.88 and a RPD of 2.97 . The variability in the composition of independent batches could be a possible reason for the prediction errors observed while estimating fat and moisture in both modes. The $R_{p}^{2}$ for fat and moisture were similar under both modes, SEPs in the on-line mode were lower, which may be attributed to the reason that a greater surface area of the sample was scanned by the NIR probes, producing a better representation of the sample composition. However, when $F$-test was performed no significant differences were observed between models in both modes. It should be noted that bias values obtained under on-line mode were much higher as compared to at-line mode which could be related to various external factors mentioned earlier.

Fig. 3 show the relationship between the measured and predicted values for fat for batch 3 by the PLSR approach. It is evident from Fig. $3 \mathrm{a}$ and $\mathrm{b}$ that an effect due to external factors is higher under on-line mode and is directly related to fat content, which can be observed from the diversion in the slope of regression line. High batch to batch variability of the meat samples and height differences encountered during on-line mode could be the main factors influencing the bias. Similar reasons could also be attributed to the bias observed in moisture content predictions (Fig. 4 a and b). In an industrial environment, external factors such as instrumental variations (instrument temperature, wavelength 
shifts, illumination source stability etc.) and sample variations (sample temperature, sample homogeneity, height differences between probes and the sample etc.) greatly influences the generated models. In order to overcome the influence of these factors it is important to understand the sample matrix, environment, variations in the sample and environment that are independent of the attribute of interest and effect of these external factors on the respective spectra. Implementation of extensive experimental designs such as RSM (response surface methodology), Taguchi and others could be useful in identifying and measuring the effect of these external factors. Once measured, then it could be possible to remove the effects with the use of various chemometric techniques (Alexandrakis 2012). Optical methods, bias correction and orthogonal methods are few approaches which can be implemented to achieve model robustness and require separate studies (Zeaiter and others 2006; Roger and others 2008).

\section{Conclusions}

The performance of PLSR models when applied to batch 3 were found to be accurate with high coefficients of determination $\left(R_{p}^{2}\right)$ and residual predictive deviation (RPD) and low standard errors of predictions (SEP). SEPs in on-line mode were marginally lower than at-line possibly due to a larger scanning area encountered by the NIR probes, which in turn provided a better representation of the sample composition. However, when $F$-test was performed no significant differences were observed between models in both modes. The bias values obtained under on-line mode were much higher as compared to at-line mode, which could be related to various external factors mentioned earlier.

. Since the equipment consists of four probes at different points; spatial information can be obtained using this technique from multiple angles providing advantages over approaches such as hyperspectral imaging. It can be concluded from the overall results that NIR spectrophotometry has considerable prospects for performing in-line monitoring of food products. In order to use the system for practical applications, prediction errors can be reduced with larger batch size. Moreover, the use of extensive experimental designs, chemometrics and other corrective techniques could be utilized in order to remove the influence of various external factors and thus build robust calibration models for in-line monitoring under industrial conditions.

Multipoint NIR spectroscopy holds great potential for the food industry with the provision of spectral and spatial information under real time conditions.

\section{Author Contributions}

Y. Dixit collected test data and drafted the manuscript.

Maria P. Casado-Gavalda performed experiments and interpreted the results.

R. Cama-Moncunill performed experiments.

P. J. Cullen edited the manuscript.

Carl Sullivan designed the study.

\section{References}

Alexandrakis D. 2012. NIRS in an industrial environment. Near Infrared Supplement. p. 3-6.

Alexandrakis D, Downey G, Scannell AG. 2012. Rapid non-destructive detection of spoilage of intact chicken breast muscle using near-infrared and Fourier transform mid-infrared spectroscopy and multivariate statistics. Food and Bioprocess Technology 5(1):338-47.

Andres S, Murray I, Navajas EA, Fisher AV, Lambe NR, Bunger L. 2007. Prediction of sensory characteristics of lamb meat samples by near infrared reflectance spectroscopy. Meat science 76(3):509-16.

AOAC. 2000. Official methods of analysis. 17th edition. Gaithersburg, MD, USA, Association of Analytical Communities. 
Bakeev KA. 2010. Process analytical technology: spectroscopic tools and implementation strategies for the chemical and pharmaceutical industries: John Wiley \& Sons.

Boylston T, Chen F, Coggins P, Hydlig G, McKee L, Kerth C, Nollet LM. 2012. Handbook of meat, poultry and seafood quality: John Wiley \& Sons.

Bruun S, Jensen JW, Magid J, Lindedam J, Engelsen SB. 2010. Prediction of the degradability and ash content of wheat straw from different cultivars using near infrared spectroscopy. Industrial Crops and Products 31(2):321-6.

Cozzolino D. 2015. Foodomics and infrared spectroscopy: from compounds to functionality. Current Opinion in Food Science 4:39-43.

Cozzolino D, De Mattos D, Martins DV. 2002. Visible/near infrared reflectance spectroscopy for predicting composition and tracing system of production of beef muscle. Animal Science $74: 477-84$.

Dixit Y, Casado-Gavalda MP, Cama-Moncunill R, Cama-Moncunill X, Jacoby F, Cullen P, Sullivan C. 2016a. Multipoint NIR spectrometry and collimated light for predicting the composition of meat samples with high standoff distances. Journal of Food Engineering 175:58-64.

Dixit Y, Casado-Gavalda MP, Cama-Moncunill R, Markiewicz-Keszycka M, Cruise P, Jacoby F, Cullen P, Sullivan C. 2016b. NIR spectrophotometry with integrated beam splitter as a process analytical technology for meat composition analysis. Analytical Methods 8(20):4134-41.

ElMasry G, Sun D-W, Allen P. 2013. Chemical-free assessment and mapping of major constituents in beef using hyperspectral imaging. Journal of Food Engineering 117(2):235-46.

FAO's Animal Production and Health Division: Meat \&amp; Meat Products. [Accessed 201521 MARCH] Available from: http://www.fao.org/Ag/againfo/themes/en/meat/home.html.

Food and Drug Administration Center for Drug Evaluation and Research (CDER). MAR 2015. DEVELOPMENT AND SUBMISSION OF NEAR INFRARED ANALYTICAL PROCEDURES: Guidance for Industry. In: U.S. Department of Health and Human Services, editor: Author.

Gowen A, O’Donnell C, Cullen PJ, Bell S. 2008. Recent applications of chemical imaging to pharmaceutical process monitoring and quality control. European journal of pharmaceutics and biopharmaceutics 69(1):10-22.

Hoving-Bolink A, Vedder H, Merks J, De Klein W, Reimert H, Frankhuizen R, Van den Broek W. 2005. Perspective of NIRS measurements early post mortem for prediction of pork quality. Meat science 69(3):417-23.

Kerth CR, Harbison AL, Smith SB, Miller RK. 2015. Consumer sensory evaluation, fatty acid composition, and shelf-life of ground beef with subcutaneous fat trimmings from different carcass locations. Meat science 104:30-6.

Makky M, Soni P. 2014. In situ quality assessment of intact oil palm fresh fruit bunches using rapid portable non-contact and non-destructive approach. Journal of Food Engineering 120:248-59.

Meza-Marquez OG, Gallardo-Velazquez T, Osorio-Revilla G. 2010. Application of mid-infrared spectroscopy with multivariate analysis and soft independent modeling of class analogies (SIMCA) for the detection of adulterants in minced beef. Meat science 86(2):511-9.

Misra NN, Sullivan C, Cullen PJ. 2015. Process Analytical Technology (PAT) and Multivariate Methods for Downstream Processes. Current Biochemical Engineering 2(1):4-16.

Moreira SA, Sarraguça J, Saraiva DF, Carvalho R, Lopes JA. 2015. Optimization of NIR spectroscopy based PLSR models for critical properties of vegetable oils used in biodiesel production. Fuel 150:697-704.

Morsy N, Sun DW. 2013. Robust linear and non-linear models of NIR spectroscopy for detection and quantification of adulterants in fresh and frozen-thawed minced beef. Meat science 93(2):292302.

Prado N, Fernández-Ibáñez V, González P, Soldado A. 2011. On-site NIR spectroscopy to control the shelf life of pork meat. Food Analytical Methods 4(4):582-9. 
Prieto N, Andrés S, Giráldez FJ, Mantecón A, Lavín P. 2006a. Potential use of near infrared reflectance spectroscopy (NIRS) for the estimation of chemical composition of oxen meat samples. Meat science 74(3):487-96.

Prieto N, Andres S, Giraldez FJ, Mantecon AR, Lavin P. 2006b. Potential use of near infrared reflectance spectroscopy (NIRS) for the estimation of chemical composition of oxen meat samples. Meat science 74(3):487-96.

Prieto N, Roehe R, Lavin P, Batten G, Andres S. 2009. Application of near infrared reflectance spectroscopy to predict meat and meat products quality: A review. Meat science 83(2):175-86.

R Core Team. 2014. R: A language and environment for statistical computing. R Foundation for Statistical Computing, Vienna, Austria, 2012. ISBN 3-900051-07-0.

Ranken MD. 2000. Handbook of meat product technology: Blackwell Science Oxford.

Roger J-M, Chauchard F, Williams P. 2008. Removing the block effects in calibration by means of dynamic orthogonal projection. Application to the year effect correction for wheat protein prediction. Journal of Near Infrared Spectroscopy 16(3):311-5.

Scheibelhofer O, Balak N, Koller D, Khinast J. 2013. Spatially resolved monitoring of powder mixing processes via multiple NIR-probes. Powder Technology 243:161-70.

Tøgersen G, Arnesen JF, Nilsen BN, Hildrum KI. 2003. On-line prediction of chemical composition of semi-frozen ground beef by non-invasive NIR spectroscopy. Meat science 63(4):515-23.

Tøgersen G, Isaksson T, Nilsen B, Bakker E, Hildrum K. 1999. On-line NIR analysis of fat, water and protein in industrial scale ground meat batches. Meat science 51(1):97-102.

Toldrá F. 2010. Handbook of meat processing: John Wiley \& Sons.

Wold J, O'Farrell M, Høy M, Tschudi J. 2011. On-line determination and control of fat content in batches of beef trimmings by NIR imaging spectroscopy. Meat science 89(3):317-24.

Zeaiter M, Roger J, Bellon-Maurel V. 2006. Application to NIR-based monitoring of wine fermentations. Chemometrics and Intelligent Laboratory Systems 80(2):227-35. 
Tables

Table 1. Moisture and fat composition of minced lean beef and beef fat trimmings per independent experiment (batch).

\begin{tabular}{llll}
\hline & & \% Moisture & \% Fat \\
& & & \\
\hline & Batch1 & 73.32 & 2.63 \\
Minced & & $( \pm 0.04)$ & $( \pm 0.24)$ \\
lean beef & Batch2 & $(73.28-73.35)$ & $(2.42-2.88)$ \\
\cline { 2 - 4 } & & $( \pm 0.22)$ & 3.26 \\
& & $(72.27-72.70)$ & $( \pm 0.17)$ \\
& Batch3 & 72.67 & $2.96-3.38)$ \\
& & $( \pm 0.40)$ & $( \pm 0.21)$ \\
& & $(72.37-73.12)$ & $(2.75-3.16)$ \\
\hline \multirow{4}{*}{$\begin{array}{lll}\text { Beef fat } \\
\text { trimmings }\end{array}$} & Batch1 & 12.78 & 83.92 \\
& & $( \pm 0.58)$ & $( \pm 0.41)$ \\
\cline { 2 - 4 } & & $(12.22-13.38)$ & $(83.55-84.35)$ \\
\hline & & 18.76 & 73.56 \\
& & $( \pm 4.39)$ & $( \pm 8.09)$ \\
\cline { 2 - 4 } & & $(15.38-23.72)$ & $(64.38-79.62)$ \\
\hline & Batch3 & 23.57 & 65.73 \\
& $( \pm 0.41)$ & $( \pm 1.25)$ \\
& & $(23.22-24.02)$ & $(64.29-66.49)$ \\
\hline
\end{tabular}

Standard deviation shown in brackets, preceded by the symbol $\pm(n=3)$.

Numbers in brackets below standard deviations correspond to the minimum and maximum values respectively. 


\begin{tabular}{|c|c|c|c|c|c|c|c|c|c|c|}
\hline \multirow[b]{3}{*}{ Attribute } & \multicolumn{10}{|c|}{ At-line } \\
\hline & \multicolumn{6}{|c|}{ Calibration } & \multicolumn{4}{|c|}{ Validation } \\
\hline & $R_{c}^{2}$ & SEC & RPD & $R_{c v}^{2}$ & SECV & RPD & $R_{p}^{2}$ & bias & SEP & RPD \\
\hline Fat & 0.97 & 4.30 & 6.24 & 0.96 & 4.30 & 4.97 & 0.87 & 3.89 & 6.84 & 2.87 \\
\hline Moisture & 0.98 & 3.03 & 6.65 & 0.96 & 3.03 & 5.58 & 0.92 & -1.24 & 4.72 & 3.63 \\
\hline & \multicolumn{10}{|c|}{ On-line } \\
\hline Fat & 0.97 & 4.89 & 5.49 & 0.95 & 4.89 & 4.35 & 0.82 & 6.95 & 5.95 & 2.43 \\
\hline Moisture & 0.96 & 3.87 & 5.21 & 0.94 & 3.87 & 4.14 & 0.88 & -4.01 & 4.33 & 2.97 \\
\hline
\end{tabular}

Table 2. Performance of PLSR models for predicting fat and moisture content of the test data set (batch 3) in at-line as well as on-line conditions 
Figures
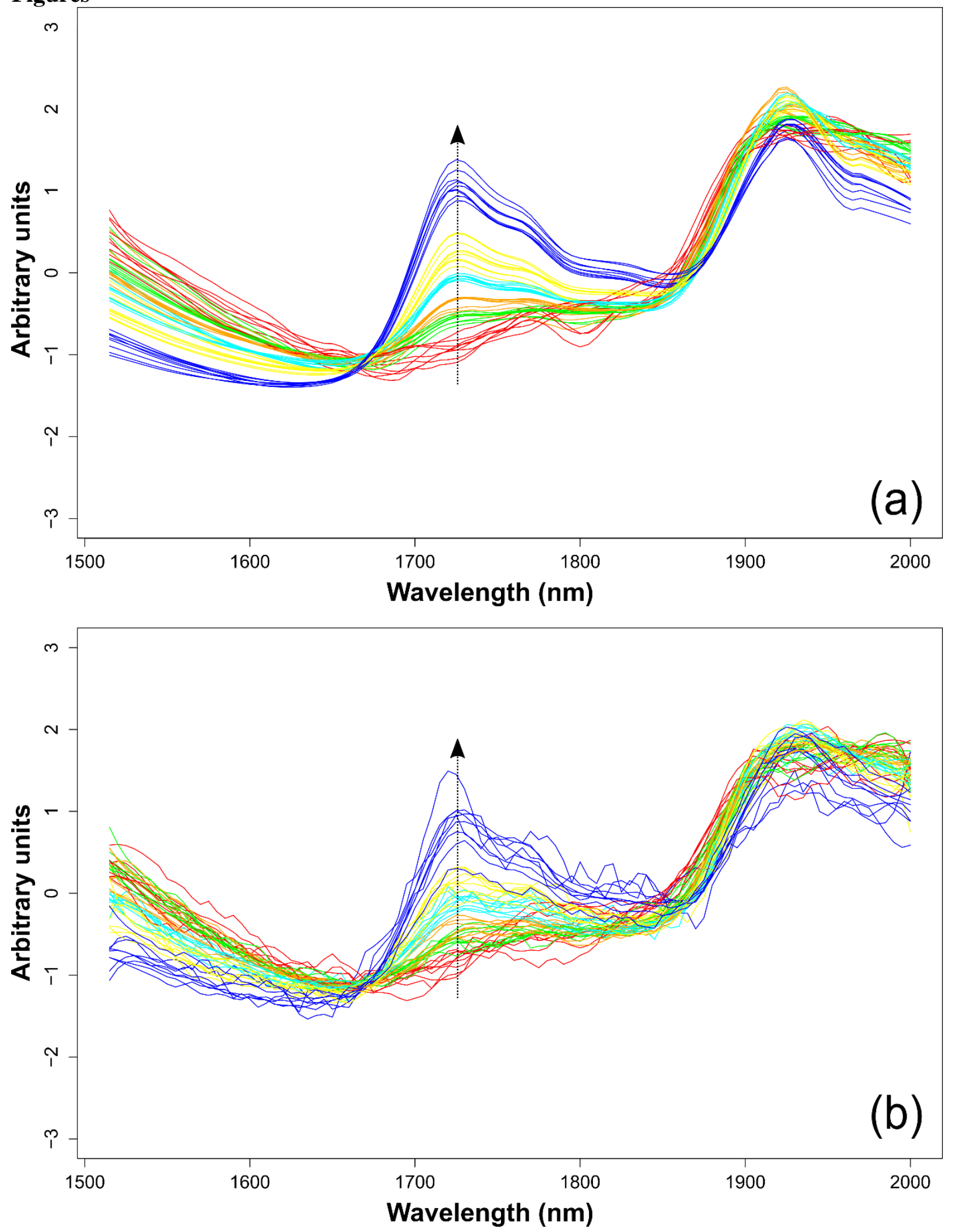

Fig.1 SNV transformed and smoothed NIR spectra of the minced beef samples at different fat levels: (a) At-line mode and (b) On-line mode (The arrow indicates the direction of increasing content of fat trimmings). 


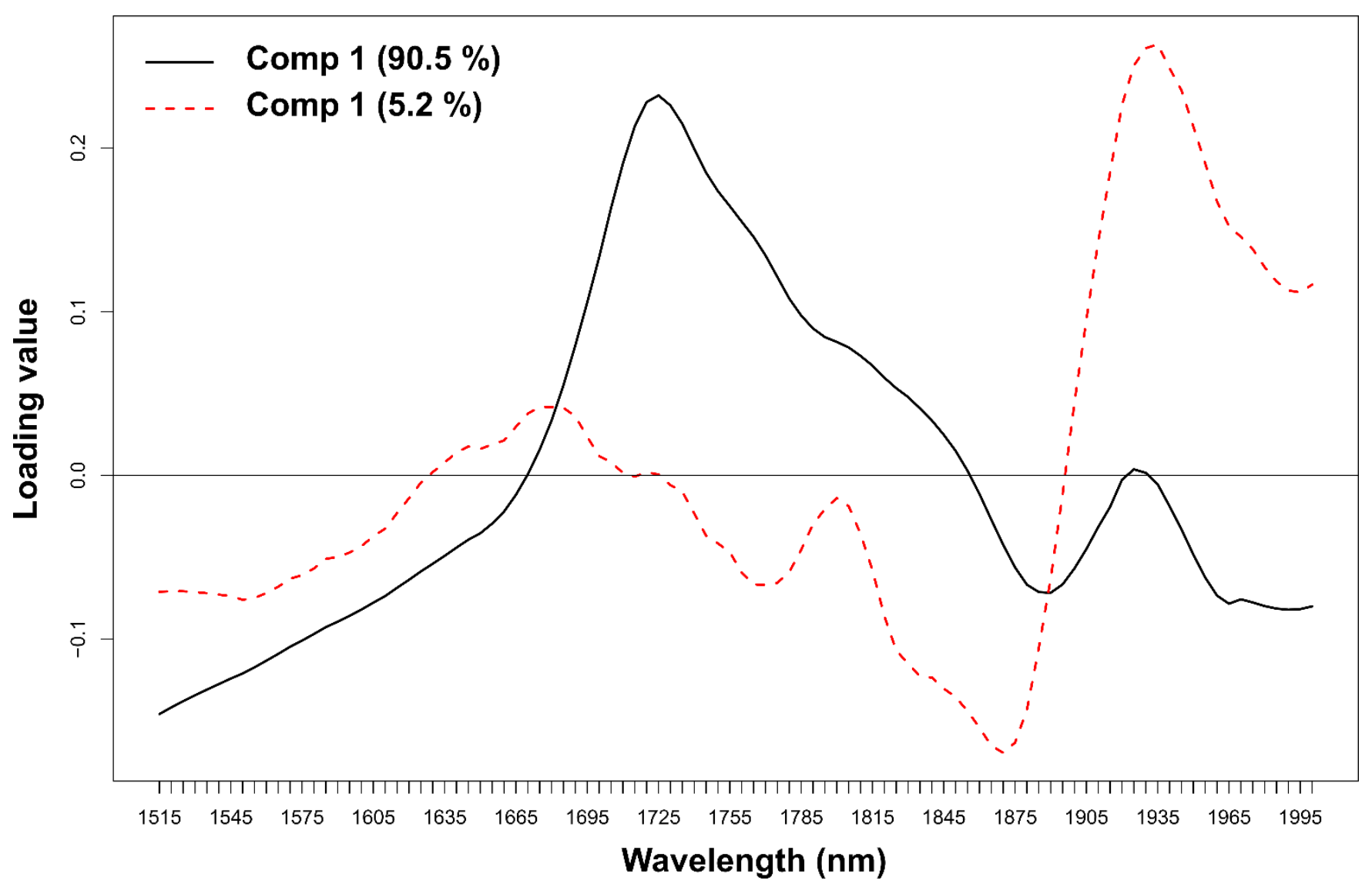

Fig. 2. PLS main loadings plot for samples with respect to the fat model in at-line mode 

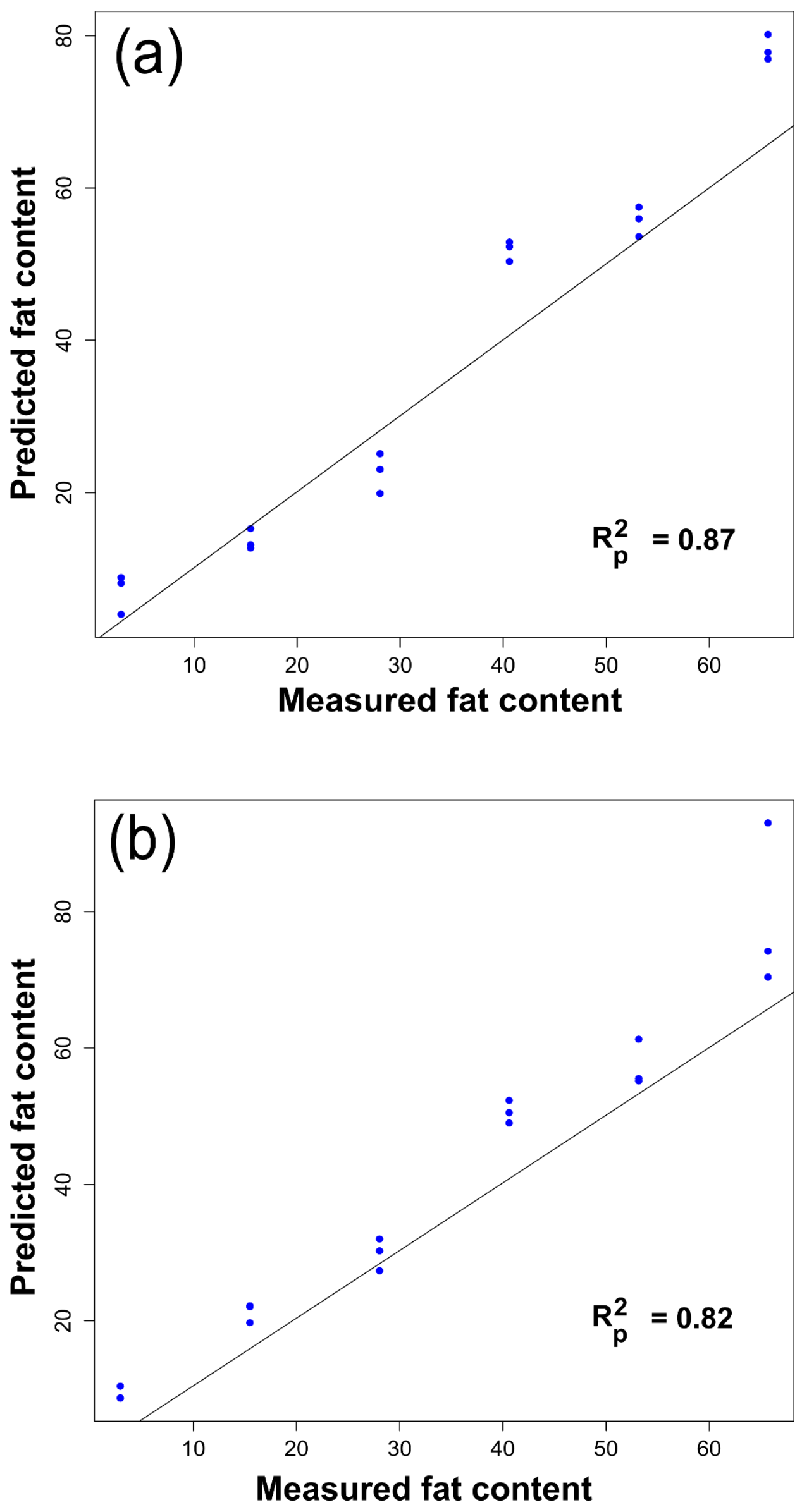

Fig. 3. Prediction plots for the independent batch 3: (a) at-line and (b) on-line modes for fat. 

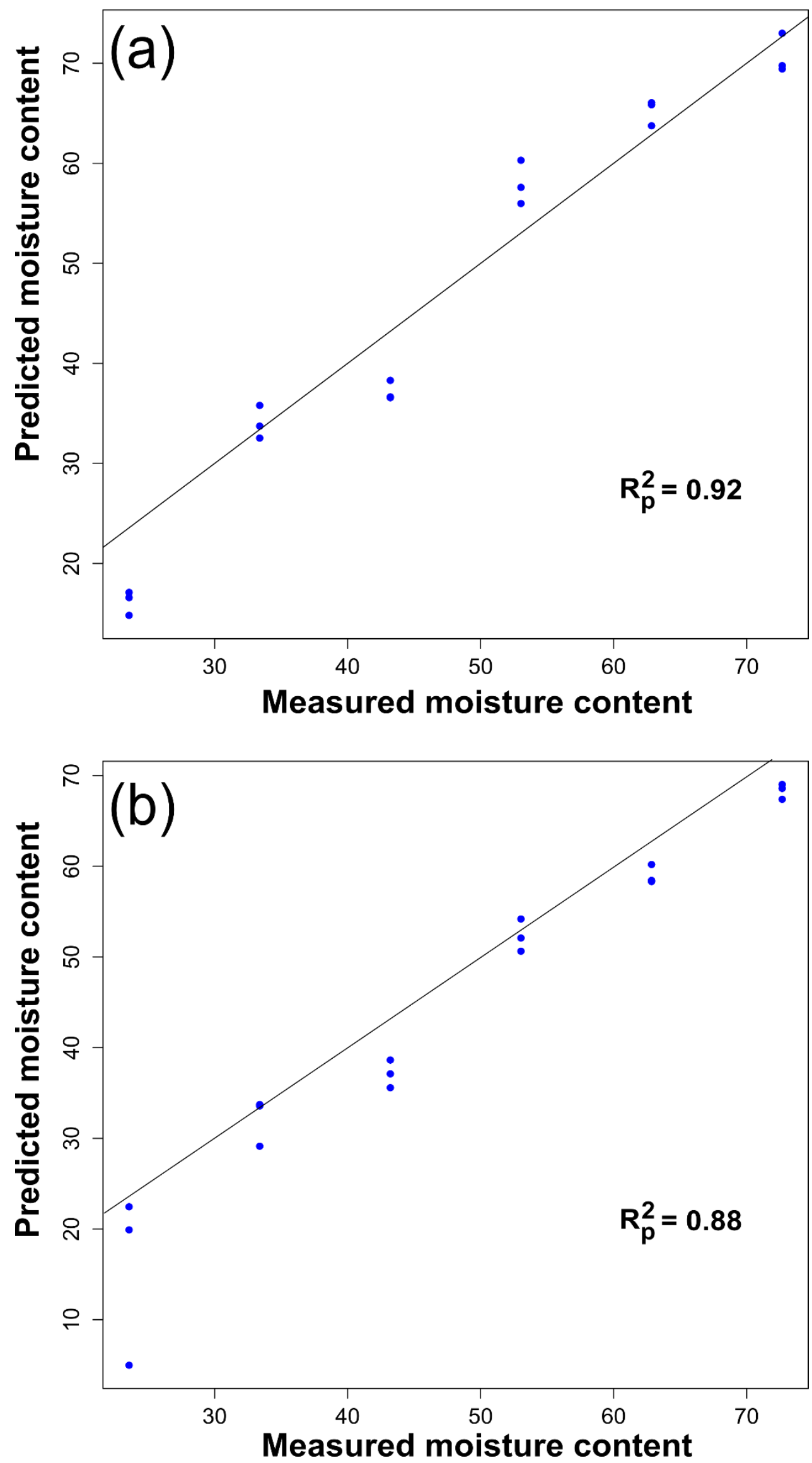

Fig. 4. Prediction plots for the independent batch 3: (a) at-line and (b) on-line modes for moisture. 